\title{
Cannabis Consumption and Stigma Labels Among Consumers in a Rural Community in Ebonyi State, Nigeria
}

\author{
Joseph Ogbonnaya Alo Ekpechu ${ }^{1}$, Innocent Ahamefule Nwosu ${ }^{1}$, Nsidibe A. Usoro ${ }^{2}$, Kennedy Okechukwu Ololo ${ }^{1}$, \\ Vivian Chizoma Njemanze ${ }^{1}$, Ethelbert Okoronkwo ${ }^{1} \&$ Bukola Popoola $^{1}$ \\ ${ }^{1}$ Sociology Department Faculty of Management and Social Sciences Alex Ekwueme Federal University \\ Ndufu-Alike Ikwo Ebonyi State, Nigeria \\ ${ }^{2}$ Department of Sociology and Anthropology University of Uyo Uyo Akwa Ibom State, Nigeria \\ Correspondence: Joseph Ogbonnaya Alo Ekpechu, Sociology Department Faculty of Management and Social \\ Sciences Alex Ekwueme Federal University Ndufu-Alike Ikwo Ebonyi State, Nigeria. Tel: 234-806-474-4193. \\ E-mail: ogbonnaya_ekpechu@yahoo.com
}

Received: September 9, 2019 Accepted: November 28, 2019 Online Published: January 30, 2020

doi:10.5539/gjhs.v12n2p106 URL: https://doi.org/10.5539/gjhs.v12n2p106

\begin{abstract}
This study examined the influence of labels used to stigmatise cannabis consumers on the control of cannabis consumption in a Community in Ebonyi State, Nigeria. Three research objectives were raised to guide the study. The questionnaire was used to get information on the socio-demographic variables of the respondents. Focus group discussion (FGD) sessions was thereafter conducted in five different places $(\mathrm{N}=55, \mathrm{n}=11)$. Responses from study participants to FGD questions were transcribed verbatim. Three themes emerged in the process. These themes include stigma labels and its deterrent effectiveness on cannabis consumption, stigma labels and differentiation of cannabis consumers from non-consumers and stigma labels and deterrence of public consumption of cannabis. It was found among other things that labels were often used by non-cannabis consumers to stigmatise the cannabis consumers with derogatory name calling as its major preoccupation. This was not an effective tool in deterring cannabis consumers from cannabis use. It was recommended that other researches should focus only on cannabis users to see how they respond to it. It was concluded that counselling should be extended to cannabis users who live in the rural areas of Nigeria.
\end{abstract}

Keywords: cannabis consumers, labels, non-cannabis consumers, rural areas, stigmatise

\section{Introduction}

Cannabis is a substance that is consumed by some individuals in the society. No wonder it has been estimated that $147,000,000$ people ( $2.5 \%$ of the population of the world) are on the habit of consuming cannabis annually (WHO 2017). This shows clearly that the substance is consumed by different people usually in higher proportions. The West African sub region, where Nigeria belongs is one of the regions bedeviled by this cankerworm (International Statistics, 2017; Civilised, 2017). There could be different factors which could affect the use of cannabis, which usually creates variations in its rate of use across different societies. This may include among others users' age, the kind of religion professed, level of income available to them and their levels of educational attainment among others.

Many Nigerians also consume the substance which is distributed to interested buyers in different communities in the country. Efforts made by different law enforcement agents like the National Drug Law Enforcement Agency and the Nigerian police in seizure of the products and the arrest of some sellers and some users alike seem to be yielding less result. Sometimes the farm lands where the cannabis plants are cultivated are often destroyed in order to discourage its use. It is still a surprise to many why some Nigerians residing in the rural communities still use the substance (Dailywire, 2017; WHO, 2017, United Nations Office on Drugs and Crime (UNODC), 2014; Obinna, 2013; Nwakunor, Akutu, Ahovi, Akingboye, Anwar, \& Todo, 2016).

Continuous and rampant use of cannabis by some rural dwellers in rural communities in Nigeria could have necessitated the use of different labels to stigmatise the users of the substance by the non-users alike. This could be a pointer to the total rejection of its use by some people, hence the labels. That many people now use cannabis does not preclude same from stigma which could pose some challenges to users (Hathaway, 2010; Hathaway, Comeau, 
\& Erickson, 2011). This may lead to rejection which could make re-integration difficult (Gagnon, 2015), damage a person's self-esteem (Villa, 2018), which could affect receipt of treatment and support by the affected individuals (Satterlund, Lee, \& Moore, 2016; UK Essays, 2017). However, some users of the substance who lead a descent life could use this medium to run away from stigma even as they continue to take the unlawful substance (Sanger, 2017). Salient strategies could be put up to reduce cannabis-use-related stigma in the society (Bottorf, Bissell, Balneaves, Oliffe, Capler, \& Buxton, 2013). This would go a long way to turning the negative based act into a positive based reality leading to its good use by individuals in any given society. Such issues as strength of stigma labels on deterrence, classification and public consumption of cannabis have not been fully tackled by authors, hence the need for this study.

The frequent use of cannabis by many in the rural communities in Nigeria has raised the concern of individuals, governments and concerned organisations. The societal members seem to frown at use of cannabis. Efforts made by individuals, governments and other concerned organisations to curb use of cannabis in the communities seem to be yielding less results. Authors and/or researches have done works on cannabis use in Nigeria. However, studies have not shown enough works on the relationship existing between stigma labels and cannabis use. This study made efforts to bridge this gap in knowledge. This study therefore examined the deterrent effectiveness of stigma labels on cannabis consumption based on gender considerations. Specifically, the study sought to examine the effectiveness of stigma labels in deterring cannabis consumption. Secondly, it sought to examine the strength of stigma labels in differentiating cannabis consumers from non-consumers. Thirdly, it examined the strength of stigma labels in deterring public consumption of cannabis. Recommendations were given based on the findings of the study.

\subsection{Theoretical Framework}

George Herbert Mead, Williams James and Charles Horton Cooley's symbolic interactionist perspective (also known as symbolic interactionism S.I.) could explain the relationship existing between stigma (derogatory labels from non-users) and the users. The theory views human beings as living in a world of meaningful objects and other people. Meanings are created in the events following the continuous consumption of cannabis by certain people often called cannabis consumers (Nnonyelu, 1997; Egbue \& Edokobi, 2002; Schaefer, 2001)). It is usually evident seeing non-users of cannabis calling the users with different kinds of names because of the meanings they have attached to its consumption. Most times these labels could over-shadow their real names and/or their real identities. These labels could be used to depict the rejection of its normality of use. The calling of such names would certainly tell the users that the use of the substance is not acceptable by many. It could also depict an informal way of controlling its use. At other times the labels could show that certain segments of the population take cannabis while the others do not. All these emanate from the kinds of relationships existing between the users and the non-users. For instance, a non-user could have seen, lived and/or living with, and could be friends or even enemies to the user(s). The non-users could therefore stigmatise the users differently owing to the above factors. The way someone who has seen a cannabis consumer stigmatises the users could be different from the way a person who has not seen one relates with and/or stigmatise them. The way those who live with cannabis consumers stigmatise the users could be different from the way a person who is a friend to one of the users could stigmatise them. This rests on the function of the relationship existing between the users and the non-users. From these interactions, different meanings could be created one by non-users and another by users. The positive interpretation of these meanings by users could lead to a possible reduction and/or total stoppage of cannabis use by some users of the substance. The reverse could be the case for others.

\section{Methods}

\subsection{Design}

The qualitative research design was used to get information from participants. The focus group discussion sessions were conducted in five different areas in the community. The first, second, third, fourth and fifth sessions of focus group discussions had eleven participants each. This was to uncover the effectiveness of stigma labels in deterring cannabis use. In doing this, the consents of the participants were sought before they were used as participants. Those who declined were not used as participants. There were six questions that were structured to cover the study objectives. Each of the questions was clearly explained to the participants for a better understanding of the issues at stake. The research questions were the guiding principles in the formulation of the FGD guide. This was in a bid to make sure that all the objectives of the research were adequately covered in order for an accurate data to be gotten.

The language of the discussion was English Language but the participants who needed explanations in Igbo Language were given the opportunity of each question being explained to them in Igbo Language. Afterwards the discussions continued in English Language. 


\subsection{Setting and Informants}

The study was carried out in a rural community in Ebonyi State, Nigeria because there have been reported and eye witnessed incidences of cannabis use in the area. The people of the community are predominantly Igbo speaking people. They are bounded in the North by Ezzama, South by Onicha, East by Isu and West by Ugwulangwu. Majority of the people are predominantly farmers. Some women also engage in mat making as their major occupation. The community has an Eze Ogo the traditional ruler of the community, traditional prime minister and village chiefs and village chairmen.

Participants for the FGDs contained individuals who have seen, who are friends to and have lived with cannabis consumers. Efforts were made to find out those who met the inclusion criteria. As a result, those who have seen cannabis users, are friends to cannabis users and have lived with and/or still live with cannabis users as at the time of carrying out the research were qualified to be used as study participants. The researchers went from one village to another looking for individuals who qualified to be used as participants. In doing this, different persons were asked questions pertaining to the inclusion criteria. Those who gave positive responses relevant to the inclusion criteria and consented to be studied were then used as participants $(\mathrm{N}=55 ; \mathrm{n}=11$, where $\mathrm{N}$ is the total number of participants and $\mathrm{n}$ is the number of participants in each of the five sets of focus group discussion sessions). The age of participants ranged from 18 to 65 . The FGD sessions comprised participants who shared similar characteristics like literate males, literate females, non-literate males, non-literate females and male and female farmers combined. The 55 persons were then used as participants. The research was carried out from September 2017 to January 2018. Five days were spent in the FGDs.

The participants during their selection process hinted that they would only be available on Saturdays from 2:00PM to 5:00PM. Saturdays were also convenient for the researchers hence its choice. This informed the decision of the researchers to carry out the FGDs on Saturdays only for convenience. There were series of opinions coming from some participants which prompted further discussions on the subject matter. This undoubtedly made the discussion to last for up to three hours. The participants were then entertained with snacks and soft drinks immediately after each FGD session (Digestive Biscuits $=59$; Amstel Malt $=55$, Grand Malt =4). It was calmly explained to the participants that there would be no stipends to be given to them. This was to allow them to be neutral in giving their views.

\subsection{Data Collection}

The FGD guide was semi-structured in order to help participants to give their views on the subject matter as much as they could. The qualitative research design was complimented with a closed ended questionnaire which was used mainly to get the socio-demographic variables of the study participants. The copies of the questionnaire were self-administered to participants shortly before each discussion began. Eleven hours were spent in the whole focus group discussion sessions. This gave an average of 2.2 hours per FGD. Notes were taken by the researchers simultaneously at each FGD session. The questions in the focus group interview guide were repeated to all the participants in their different sessions for their input. The discussions were also taped in order to make sure that no information is lost in the process. The notes were compared with the audio taped information during the researchers' meetings. They were eight meetings that were held by the researchers before a consensus was reached on the accuracy of the information. We probed further into the questions in order to get more information from the participants. The lead researcher moderated the sessions. A time keeper was always around to help in controlling the time spent by each participant so that all the participants could have equal opportunities of lending their views on the subject matter.

\subsection{Data Analysis}

Information gotten from participants was transcribed separately by the researchers. These were collated and harmonised during our meetings. During the meetings there was rigorous questioning by each of the researchers which enabled us to get the best of the analysis. Coupled with that, each member was meant to go through each other's analysis. The reviews helped to produce an analysis of high quality. Three themes emerged in the course of the analysis. These include:

Theme I: Stigma labels and its deterrent effectiveness on cannabis consumption.

Theme II: Stigma labels and differentiation of cannabis consumers from non-consumers.

Theme III: Stigma labels and deterrence of public consumption of cannabis.

Quotes from participants were used to support these themes for clearer understanding. 


\subsection{Scientific Rigor}

The work was subjected to scientific processes in order to make it more trustworthy. In this way efforts were made to ask questions that were in line with the objectives of the study. These questions were reviewed severally by our research team for suitability. In the process the irrelevant questions were removed and new commensurate questions set. The research team made sure that no identifying object was used in transcribing the responses from the informants. Besides, regular meetings by the research team also helped to make the work more credible. We also had a consultant who is knowledgeable in the area. His rich qualitative standing and useful advice helped to improve the scientific nature of the work. Other critics have also made their inputs on the work. This has helped to improve its quality.

\section{Results}

Thirty of the participants were males while twenty five were females. Ten participants were from eighteen to thirty years. Twelve participants were from thirty one to forty three years. Twenty participants were from forty four to fifty five years. Thirteen participants were from fifty six years and above. Forty nine participants could speak English and Igbo Languages fluently. Six participants understood Igbo Language more than English Language but spoke both. There were twenty literate males, eleven literate females, ten non-literate males and fourteen non-literate females. Forty of the participants were married while fifteen of them were still single as at the time the study was being conducted. The participants all lived in the rural setting. Thirty of the participants lived and/or were still living with cannabis consumers. Ten participants had seen cannabis consumers but did not live with them. Fifteen participants were friends to cannabis consumers but had not lived with them. None of the study participants were enemies to the cannabis consumers (table one).

Table 1. Socio-demographic Characteristics of Participants $(\mathrm{N}=55)$

\begin{tabular}{ll}
\hline Variable & $\mathbf{( n / \% )}$ \\
\hline Gender & $30(54.5)$ \\
Male & $25(45.5)$ \\
Female & \\
\hline Age & $10(18.2)$ \\
$18-30$ & $12(21.8)$ \\
$31-43$ & $20(36.4)$ \\
$44-55$ & $13(23.6)$ \\
56 and above & \\
\hline Language Spoken & $55(100)$ \\
English and Igbo & $0(0)$ \\
Others & \\
\hline Education & $20(36.4)$ \\
Literate Males & $11(20)$ \\
Literate Females & $10(18.2)$ \\
Non-Literate Males & $14(25.5)$ \\
Non-Literate Females & \\
\hline Marital Status & $15(27.3)$ \\
Single & $40(72.7)$ \\
Married & $55(100)$ \\
\hline Residential Area & $0(0)$ \\
Rural & \\
\hline Urban &
\end{tabular}




\section{Relationship with Cannabis Consumers}

Seen Them

Lived/Living with Them

Friends to Them

Enemies to Them

$0(0)$

Source: Fieldwork (2018).

There were three themes which emanated from the study.

\subsection{Theme I: Stigma Labels and its Deterrent Effectiveness on Cannabis Consumption}

In the course of the research some informants observed that the strength of stigma labels on cannabis deterrence varied. Naming calling was the order of the day. Non-users of cannabis usually called the users with different derogatory names. A participant said, "we call them ndi Igbo, ndi kaikai or ndi amanwu ife and dirty people all because they take cannabis. They are dirty people because some of them look very dirty and had unpleasant smells coming from their body." The participant continued by saying that, "name callings wasn't preventing them from indulging in it."

Thereafter another participant opined that his younger brother was fond oftaking the substance regularly. According to the informant,

I personally call him onye wefia - a derogatory term for a cannabis consumer in our community. Each time I call him the name he felt sorry for himself. I thought this would change his life but it doesn't. I keep on calling him the name sometimes he threatened to beat me up but I maintained my ground. The worst part of it is that other members of the community call us nwune onye wefia. We are sharing the blame of what we have no hands in. Do I have to change my family because one of us takes cannabis? Surprisingly such labels don't deter him but he even had the courage of selling the substance to others.

Cultural values play a role in assigning such labels. This was the position of another participant who maintained that "our culture sees a woman taking cannabis as a taboo. It could be heard of not seen." He also said that a female cannabis consumer live in their compound. The participant therefore said that "sometimes they behave like mad people. She often tried to fight the husband. When she has exchange of words with other women they would call her such derogatory names as woman who lives an unorganised lifestyle. In one of such occasions a woman called her a thief since they are not to be trusted." The statement by another participant was rather empathic. According to him, my son takes cannabis. I don't trust him. He behaves abnormally at times just like a mad person, a crazy boy. Sometimes he sings aloud shouting. At other times he remains very calm. People have complained severally that they see him talking to himself. Is this not a sign of madness? This boy consumes a lot of food at a time. He takes food that could belly full three persons. He is very hot tempered. I don't even know when he started taking it. As I am talking now he still takes it.

Another participant noted that she calls any cannabis consumer "hot tempered, bad person, a criminal, irresponsible person and a blatant liar whose life is awkward." She also noted that "I have never seen the cannabis consumer in question change except when there is no money on him." This successive submission by another participant carries a heavier label. "The women who take it are harlots. It baffles me that the more people talk bad of them the more they take it." "In fact any woman who takes it in our vicinity is often regarded as an irresponsible woman. Some of them beat up their husbands and even fight with other men and women. In our locality we refer to them as non-intelligent people and nonentities," another participant observed. One of the participants narrated what a cannabis consumer said which made us to laugh. "Mkpuru obu ekwe ekwe se akpoye oku. This shows the degree at which the cannabis consumers are stigmatised against in the community.

\subsection{Theme II: Stigma Labels and Differentiation of Cannabis Consumers from Non-Consumers}

Certain labels could be used to differentiate cannabis users from non-users. One of the submissions of a participant helped to bring this to limelight. According to the participant "the users smell more than the non-users. Good ones take their bath and change their clothes regularly. The tips of their nails look very black." This was further clarified by another participant who said that "usually after taking it the person's life changes and could turn to beating up people for no just course. He behaves like a mad person. I have heard that one of the consumers beat up his wife. In one occasion he went to fight in a nearby compound and he beat up the people mercilessly. He went further to break their cooking pots. There was a big confusion in our neighbourhood that very day." Also, another participant 
said that:

The cannabis consumers have their own slangs. If it is spoken you would actually know that they take cannabis. For instance when they say afia odu, one hearing it should know that those speaking it take cannabis. There is another of such slangs that interests me-achoro m ishiri. This tells us that truly the people take cannabis. They know themselves very well. I have a boy that consumes the substance. I travelled with him to another town for farm work and immediately we arrived, he started relating well with a woman. After a while I started looking for him. It was the woman who showed me where he was. Later on I came to find out that the woman sold the substance and also consumed it. The point I am trying to make is that they could identify themselves any where they go more easily. The bad boy, I mean that my boy, sometimes the substance turns his head and he would start speaking alone to himself.

\subsection{Theme III: Stigma Labels and Deterrence of Public Consumption of Cannabis}

Some participants were of the view that stigma labels could deter some people from consuming cannabis in public. "Frankly speaking we never knew she was taking cannabis until she was married into our compound. Surprisingly too she never take it in the open most especially so that people would not laugh at her. Other persons take it in public some in secret too (so as to hide their cannabis consuming identity)," a participant observed. Another participant also observed that "I am not sure that women take it. This is because I have never seen any of them take it in a public place." Similarly, "some women take it in secret because they are regarded as being wayward for taking cannabis. Because of all these they seem to take it in secret in order to cover their faces from shame. Sometimes you may not know that they take it because it is usually done in absolute secrecy. I have seen one man who sells the substance he takes it in the open but his wife is never seen taking it in the open." Twenty of the participants were of the view that many men especially youth were usually seen taking the substance in public places. "Even when you don't see them with your naked eyes the smell of the substance usually revealed that they were taking it. If you manage to see them no girl or lady would be seen among the boys." A participant submitted.

\section{Discussion}

The participants had seen 60 persons who consumed cannabis. There were nine female consumers of the substance. Labels were often used by non-cannabis consumers to stigmatise the cannabis consumers. This was an indirect way of making the consumers to desist from its consumption. The strength of this deterrence medium varied from one locality to another. As a result, name calling such as ndi igbo, onye wefia, ndi wefia, ndi kaikai, an irresponsible woman, unwise people, dirty people, mad people, crazy people, hot tempered, bad person, nonentities, a criminal, irresponsible and as a blatant liar and awkwardness was not seen by participants as being very effective in deterring cannabis consumers from its consumption. It made some users to feel sorry for taking it. To others it doesn't move them at all hence their adaptation to the derogatory terms. Family members of the consumers often times share in such derogatory terms such as nwune onye wefia. This could make such people to look for ways of making them to stop its consumption. Some users have internalised the labels and have resorted to destroying their hearts since it has refused to change.

Cultural attributes could make people to look at some women consumers as doing something which the culture abhors. This could make derogatory terms as being more effective in deterring women from consuming the substance in the open places in the area than men. These could be more effective for feeling of temporal remorse by some users. However, its absolute deterring power could be more effective for women users than for their male counterparts. This could be so because it could deter women from consuming the substance in public places than the men. This attests to the fact that no participant had seen any woman user taking the substance in the open. Rather it was affirmed that it was usually taken in secret where no one could see them taking it. Some people would know that they take it but had never seen any of them taking the substance. This feat could be attributed to the powers of stigma. The truth however remains that it is not an effective indirect form of cannabis consumption control.

Labels attached to stigma on cannabis consumption and/or cannabis consumers are more effective in differentiating cannabis consumers from non-consumers. As a matter of fact, the users smell more than the non-users. As it is there is a way a consumer would smell which is usually offensive to another's perceiving organ. Non-user of the substance would never be seen smelling that way. However, it is worthy of note that some of the users of the substance change their clothes regularly, take their bath and then apply perfume which conceals the smell. In this way it may be difficult to use theormer in differentiating users from non-users. Similarly, another form of differentiation comes from how the tips of finger nails look like. People whose finger nail tips look very black could be said to be cannabis users. This is usually different from those of the non-users. However, there could be some exceptions. Some people whose finger nail tips appear very black may also belong to the group of 
the non-users. Others whose finger nail tips appear very neat may also belong to the group of the users. Certainly, on several occasions it could be a genuine form of differentiation.

At other times people who are known to be sane could occasionally be seen behaving like mad people. When this happens people could point at them as being cannabis consumers. This is called half madness by some people. For instance, a person could be seen soliloquising quite often. The substance pushes him to always talk to himself. It also pushes him to fight usually even on trivial matters. Such persons could always appear very hot tempered especially when the substance is still active in one's body, but at other times become very calm. Non-users of cannabis could be seen quite often behaving more maturely than the users. This is not to exonerate some non-users who may as well behave that way. Some of the users claim that they think well when they use the substance but it may not be wholly true. Such manifestations may be far from the reality.

The users of cannabis have their own slangs which could be used to differentiate them from the non-users of the substance. One of such slangs is afia odu (is the wraps of cannabis available). Hearing this could enable a person know that the latter is a cannabis consumer. Achoro $m$ ishiri (I want to use cannabis) is another of such slangs. The slangs are also an effective tool of making the users to identify themselves the more even when they go to new locations. Mere speaking of the slangs could easily make one to identify with a user who would then show him the place where the substance is sold. However, some non-users of cannabis were less often seen using some of the slangs in making mockery of the cannabis users. One of the participants used it to entertain us during one of the FGD sessions. He said intermittently nwanne achoro $m$ ishiri (that he wanted to use the substance i.e. cannabis). But it was only used to mock the users, since that is the way they speak.

\subsection{Recommendations}

Apart from formal control of use of cannabis, efforts should be made by law enforcement agents to salvage certain stigma labels that could be used to deter users from its use. Counselling with the use of soft words could be used on those arrested to see if it could make them to change from being cannabis users. Cannabis based slangs could be used by law enforcement agents as a tool to arrest the users. Besides, stigma labels could be employed as an effective tool of controlling open use of cannabis. This could be used by friends, family members and other concerned individuals to make the users to shy away from using wraps of the substance openly especially in public places. When this is used to divert them to the secret use of the substance, there should be more of such labels on them to actually make them seize totally from using the substance.

Stigma labels could be used to differentiate users of cannabis from non-users. When such differentiations are made, the labels could be used more to deter users of the substance from its consumption. Family members stigmatised for their other family member(s)'s use of cannabis should make frantic efforts to make those users to change to non-users. In this way, the users and the family members hitherto stigmatised would be free from cannabis-based stigmatisation. In this way also a negative based stigma could produce a positive based respect for users who have turned to non-users and family members who were hitherto being stigmatised for their family member(s)'s involvement in cannabis consumption. This differentiating tool could be employed by non-cannabis users not to go into cannabis consumption. This would emanate from the fact that they would never in their lives want to be classified as cannabis consumers by others. They would always want to maintain their self respect. Having seen how it is to call others cannabis consumers they would desist from attempting to use the substance. This would also save them from injuring their family name.

Counselling should be extended to cannabis consumers especially those who reside in the rural areas. This should be complimented with continuous words of advice. This would necessitate positive interaction between users and non-users of cannabis ultimately leading to gradual reduction and/or stoppage of cannabis use by the former.

Other researches should replicate this study in other areas to see whether the findings could be accepted or rejected in other places. Such other studies could also focus on cannabis users only as respondents to see the extent to which stigma labels make them change from the use of the substance.

\section{Conclusion}

Rural people who do not consume cannabis use it as an avenue to stigmatise those who consume it. Name calling is one of the ways they use to label the consumers usually with derogatory names. This is an indirect means of control against cannabis consumption. Though derogatory, labelling could be a way of differentiating consumers of cannabis from non-consumers. Once the derogatory name is used on anyone it automatically designates the person as the consumer of cannabis and the other as a non-consumer.

\subsection{Limitations of the Study}


The paper is a reflection of the views of the participants who participated in the study. Such views can not be generalised for the whole persons in the community. Besides, the study did not focus on the users per se but those who have lived with them, seen or are friends and even enemies to them. As a result, there may be need for another study to consider cannabis users as participants to ascertain whether the views of the participants used for this study could be upheld or rejected. It would help researchers to know how the users respond to labels being used to stigmatise them.

\section{Authors' Note}

The authors contributed equally from the research process to the drafting of this paper.

\section{Funding}

There was no funding for the study.

\section{Acknowledgements}

We wish to thank all persons who declared interest to be used as participants for the study. Their useful contributions have helped to make this work a reality. We thank our school authorities for giving us the opportunity to carry out the study. We thank also UNODC and EU for sponsoring the work for conference presentation. This has helped to make the work better.

\section{Competing Interests Statement}

There is no conflict of interests to be declared.

\section{References}

Abha, V., Tripathy, G. P., Nazar, N. S., Juneja, L., Ramakrishman, K. and Srinath, R. (2010). Community-based model for preventing tobacco use among disadvantaged adolescents in urban slums of India. Health Promotion International, 25(2), 143-152. https://doi.org/10.1093/heapro/daq008

Adah, A., Abimaje, A., Essien, A., Chiama, P., Onu, Q., \& Sarki, Y. (2015). Nigeria: prevalent vices of the youth which way out? Retrieved 05/01/18 from http://allafrica.com/stories/201511270050.html

ADAI. (2017). Learn about marijuana Science-based information for the public. Retrieved 13/12/17 from http://learnaboutmarijuanawa.org/factsheets/whatiscannabis.htm

Adamson, T. A., Ogunlesi, A. O., Morakinyo, O., Akinhanmi, A. O., \& Onifade, P. O. (2015). Descriptive National Survey of Substance Use in Nigeria. J Addict Res Ther, 6, 234. https://doi.org/10.4172/2155-6105.1000234

Askew, R., \& Salinas, M. (2018). Status, stigma and stereotype: how drug takers and drug suppliers avoid negative labelling by virtue of their conventional and law-abiding lives. Retrieved 13/06/18 from http://journals.sagepub.com/doi/abs/10.1177/1748895818762558

Bottorf, J. L., Bissell, L. L., Balneaves, L. G., Oliffe, J. L., Rielle, N., Capler, N. R., \& Buxton, J. (2013). Perceptions of cannabis as a stigmatised medicine: a qualitative descriptive study. Harm Reduct J., 10(2). https://doi.org/10.1186/1477-7517-10-2

Civilised. (2017). Here's how many people in the world consume cannabis. Retrieved December 13, 2017, from https://www.civilised.life/articles/here-how-many-people-use-cannabis-worldwide

Dailywire. (2017). Study: how many Americans are smoking pot? The number is nuts. Retrieved December 13, 2017, from http://www.dailywire.com/news/8242/study-how-many-americans-are-smoking-pot-numberpardes-seleh

Egbue, N., \& Edokobi, A. C. (2002). Sociology: an introduction. Enugu: Oktek Publishers.

Federal Republic of Nigeria Official Gazzette. (1991). Legal notice on publication of the details of the breakdown of the national and state provisional totals 1991. Lagos: Federal Government Printer.

Gagnon, S. M. (2015). Social stigma and substance use: why language matters. Retrieved 02/06/18 from http://smartapproaches.bangordailynews.com/2015/12/04/recovery/social-stigma-and-substance-use-why-la nguage-matters/

Hathaway, A. D. (2010). Cannabis users' informal rules for managing stigma and risk. https://doi.org/10.1080/01639620490484095

Hathaway, A. D., Comeau, N. C., \& Erickson, P. G. (2011). Cannabis normalisation and stigma: contemporary practices of moral regulation. Retrieved October 6, 2018, from http://journals.sagepub.com/doi/abs/10.1177/1748895811415345?journalCode=crjb 
International Statistics. (2017). Foundation for a drug free world. Retrieved December 9, 2017, from http://www.drugfreeworld.org/drugfacts/marijuana/international-statistics.html

Musbau, R. (2012). Marijuana and the challenge of curbing crimes. Retrieved December 14, 2017, from http://www.pmnewsnigeria.com/2012/09/20/marijuana-and-the-challenge-of-curbing-crimes/

Nnonyelu, N. A. (1997). The use of exchange theory and symbolic interactionism in Sociological inquiry. In N. A. Nnonyelu and O. A. Obiajulu (Eds.), Contemporary issues in Sociology (pp. 62-75.). Enugu: John Jacob's Classic Publishers Ltd.

Nwakunor, G. A., Akutu, G., Ahovi, I. A., Akingboye, O., Anwar, A., \& Todo, T. (2016). Drug exposure and saving youths from addiction. Retrieved September 15, 2017, from http://guardian.ng/sunday-magazine/drug-exposure-and-saving-youths-from-addiction/TheGuardianSunday Magazine

Obinna, C. (2013). Young adults highest users of marijuana, others in Nigeria. Retrieved November 14, 2017 from http://www.vanguardngr.com/2013/07/young-adults-highest-users-of-marijujana-others-in-nigeria-poll/othe rs-

Sanger, B. (2017). 10 reasons why the stigma of using cannabis is melting. Retrieved 04/06/18 from https://herb.co/marijuana/news/stigma-using-cannabis

Satterlund, T. D., Lee, J. P., \& Moore, R. S. (2016). Stigma among California's medical marijuana patients. $J$ Psychoactive Drugs, 47(1), 10-17. https://doi.org/10.1080/02791072.2014.991858

Schaefer, R. T. (2001). Sociology. New York: McGraw Hill.

UK Essays. (2017). Effects of stigma on drug users. Retrieved June 13, 2018, from https://www.ukessays.com/essays/social-work/the-role-of-stigma-and-labelling-social-work-essay.php

United Nations Office on Drugs and Crime (UNODC). (2014). The World Drug Report 2014. Retrieved December 14, 2017 from http://www.ndlea.gov.ng/v1/?q=content/world-drug-report-2014-nigeria-records-highest-cannabis-seizure-a frica-1

Villa, L. (2018). Shaming the sick: addiction and stigma. Retrieved November 6, 2018, from https://drugabuse.com/library/addiction-stigma/

WHO. (2017). Management of substance abuse. Retrieved April 22, 2018, from http://www.who.int/substance_abuse/facts/cannabis/en/

\section{Copyrights}

Copyright for this article is retained by the author(s), with first publication rights granted to the journal.

This is an open-access article distributed under the terms and conditions of the Creative Commons Attribution license (http://creativecommons.org/licenses/by/4.0/). 